\title{
Real-World Effects of Antibiotic Treatment on Acute COPD Exacerbations in Outpatients: A Cohort Study under the PharmLines Initiative
}

\author{
Yuanyuan Wang ${ }^{a}$ Victor Pera ${ }^{a} \quad$ H. Marike Boezen ${ }^{b, c}$ \\ Jan-Willem C. Alffenaard, e, f Bob Wilffert ${ }^{a, g}$ Rolf H.H. Groenwold ${ }^{\text {h, } i}$ \\ Eelko Hak ${ }^{a, b}$
}

\begin{abstract}
aDepartment of PharmacoTherapy, -Epidemiology \& -Economics, Groningen Research Institute of Pharmacy, University of Groningen, Groningen, The Netherlands; ${ }^{b}$ Department of Epidemiology, University Medical Center Groningen, University of Groningen, Groningen, The Netherlands; ' ${ }^{c}$ Groningen Research Institute for Asthma and COPD (GRIAC), University Medical Center Groningen, University of Groningen, Groningen, The Netherlands;

${ }^{\mathrm{d}}$ Faculty of Medicine and Health, School of Pharmacy, University of Sydney, Sydney, NSW, Australia; 'Westmead Hospital, Sydney, NSW, Australia; ' Marie Bashir Institute of Infectious Diseases and Biosecurity, University of Sydney, Sydney, NSW, Australia; ${ }^{9}$ Department of Clinical Pharmacy \& Pharmacology, University Medical Center Groningen, University of Groningen, Groningen, The Netherlands; ' ${ }^{\text {Department }}$ of Clinical Epidemiology, Leiden University Medical Center, Leiden, The Netherlands; 'Department of Biomedical Data Sciences, Leiden University Medical Center, Leiden, The Netherlands
\end{abstract}

\section{Keywords}

Chronic obstructive pulmonary disease - Acute exacerbation · Antibiotics · Treatment failure · Outpatients · Cohort

\begin{abstract}
Background: Although antibiotic treatment is recommended for acute exacerbations of chronic obstructive pulmonary disease (AECOPD), its value in real-world settings is still controversial. Objectives: This study aimed to evaluate the short- and long-term effects of antibiotic treatment on AECOPD outpatients. Methods: A cohort study was conducted under the PharmLines Initiative. We included participants with a first recorded diagnosis of COPD who received systemic glucocorticoid treatment for an AECOPD episode. The exposed and reference groups were defined based on any
\end{abstract}

antibiotic prescription during the AECOPD treatment. The short-term outcome was AECOPD treatment failure within 14-30 days after the index date. The long-term outcome was time to the next exacerbation. Adjustment for confounding was made using propensity scores. Results: Of the 1,105 AECOPD patients, antibiotics were prescribed to 518 patients (46.9\%) while 587 patients $(53.1 \%)$ received no antibiotics. The overall antibiotic use was associated with a relative risk reduction of AECOPD treatment failure by $37 \%$ compared with the reference group (adjusted odds ratio [aOR] 0.63 [95\% Cl: 0.40-0.99]). Protective effects were similar for doxycycline, macrolides, and co-amoxiclav, although only the effect of doxycycline was statistically significant (aOR 0.53 [95\% Cl: 0.28-0.99]). No protective effect was seen for amoxicillin (aOR 1.49 [95\% Cl: 0.78-2.84]). The risk of and time to the next exacerbation was similar for both groups. Conclu- karger@karger.com www.karger.com/res

Karger $\stackrel{\text { ' }}{5}$

GOPEN ACCESS
(C) 2022 The Author(s)

Published by S. Karger AG, Basel

This is an Open Access article licensed under the Creative Common Attribution-NonCommercial-4.0 International License (CC BY-NC) (http://www.karger.com/Services/OpenAccessLicense), applicable to the online version of the article only. Usage and distribution for commercial purposes requires written permission.
Correspondence to:

Yuanyuan Wang, yuanyuanwang.research@gmail.com 
sion: Overall, antibiotic treatment, notably with doxycycline, supplementing systemic glucocorticoids reduces shortterm AECOPD treatment failure in real-world outpatient settings. No long-term beneficial effects of antibiotic treatment on AECOPD were found for the prevention of subsequent exacerbations.

(c) 2022 The Author(s)

Published by S. Karger AG, Basel

\section{Introduction}

Chronic obstructive pulmonary disease (COPD) characterized by persistent respiratory symptoms and airflow limitation is one of the leading causes of morbidity and mortality worldwide [1]. COPD patients frequently experience acute exacerbations of COPD (AECOPD), defined as acute worsening of respiratory symptoms, necessitating additional therapy [2]. AECOPD has major impacts on patients' health status, accelerates the disease progression, and increases health care costs [3]. Therefore, reducing the symptoms of current exacerbations and preventing further exacerbations are essential aspects of sound pharmaceutical management of AECOPD. AECOPD is associated with increased airway inflammations, and systemic glucocorticoid treatment is recommended to shorten the recovery time, improve lung function, and promote oxygenation, given its proven beneficial effects $[4,5]$.

The majority of AECOPD episodes are caused by respiratory infections, especially bacterial infections, which account for around $50 \%$ of all exacerbations [6]. The most widely reported bacteria associated with exacerbations are Streptococcus pneumoniae, Haemophilus influenzae, Pseudomonas aeruginosa, Moraxella catarrhalis, Acinetobacter baumannii, and Streptococcus aureus [7]. Accordingly, antibiotics have been recommended for the management of AECOPD when signs of bacterial infection are present [4]. However, the beneficial effects of antibiotic treatment in addition to oral glucocorticoid treatment for AECOPD are still uncertain among outpatients. The pooled results from 5 randomized controlled trials (RCTs) examined in a Cochrane meta-analysis conducted in 2012 did not show a significant reduced risk of treatment failure associated with currently prescribed antibiotics among outpatients [8]. However, an updated (2018) version of this Cochrane review that included 2 new RCTs $[9,10]$ presented statistically significant beneficial effects of current prescribed antibiotics among outpatients [11]. The RCT conducted by van Velzen et al. [10] contributed a large proportion (24\%) to the updated pooled results.
The limited external validity of RCTs, however, prompts questions about the effects of antibiotic treatment for AECOPD in real-world settings.

Primary care of patients with COPD is mostly managed on an outpatient basis. This population in real-world settings is more heterogeneous than those in RCTs [12]. Additionally, antibiotic treatment for AECOPD is often not in accordance with current guidelines $[13,14]$. Therefore, the real-world effects of antibiotic treatment for AECOPD may differ from those obtained from RCTs and merit further investigation. So far, only few observational studies were conducted to evaluate the treatment effects of antibiotics for AECOPD. Two of these studies focused exclusively on the long-term effects of antibiotic treatment for AECOPD and lacked any adjustment for potential differences in lung function and smoking history [15, 16]. Two other cohort studies were conducted among inpatients $[17,18]$. The PharmLines Initiative presented a unique opportunity to retrieve more information on many previously unmeasured confounders. Using an inception cohort design, we assessed the short- and longterm effects of antibiotic in addition to systemic glucocorticoids for AECOPD treatment in outpatients.

\section{Materials and Methods}

\section{Study Setting and Data Sources}

This retrospective cohort study was conducted under the PharmLines Initiative [19], which linked the Lifelines (https:// www.lifelines.nl) and the InterActionDataBase (IADB) databases (http://www.iadb.nl). Individuals included in these 2 databases are representative of the population in the northern Netherlands [20, 21 ]. Lifelines is a multidisciplinary prospective cohort study involving 167,729 participants across 3 generations from 2006 to 2017. A broad range of investigative procedures were used to assess the biomedical, sociodemographic, behavioral, physical, and psychological factors of the general population [21]. Following baseline assessments, participants underwent physical examinations at the Lifelines location every 5 years and completed extensive follow-up information collection every 1.5 years. IADB.nl is an evolving drug prescription database that currently covers prescription data for 730,000 participants from 72 community pharmacies [20]. Each patient is individually tracked throughout the database's operational period, and their prescription records contain information on the date of dispensing, the quantity of medication dispensed, the dose regimen, the number of days for which the prescription is valid, the prescribing physician, and the anatomical therapeutic chemical code. Each patient, whose date of birth and gender are recorded, is assigned a unique anonymous identifier. Due to the strong patient-pharmacy commitment in the Netherlands, the medication records for each patient are virtually complete, except for over-the-counter drugs and medication dispensed during hospitalization. 


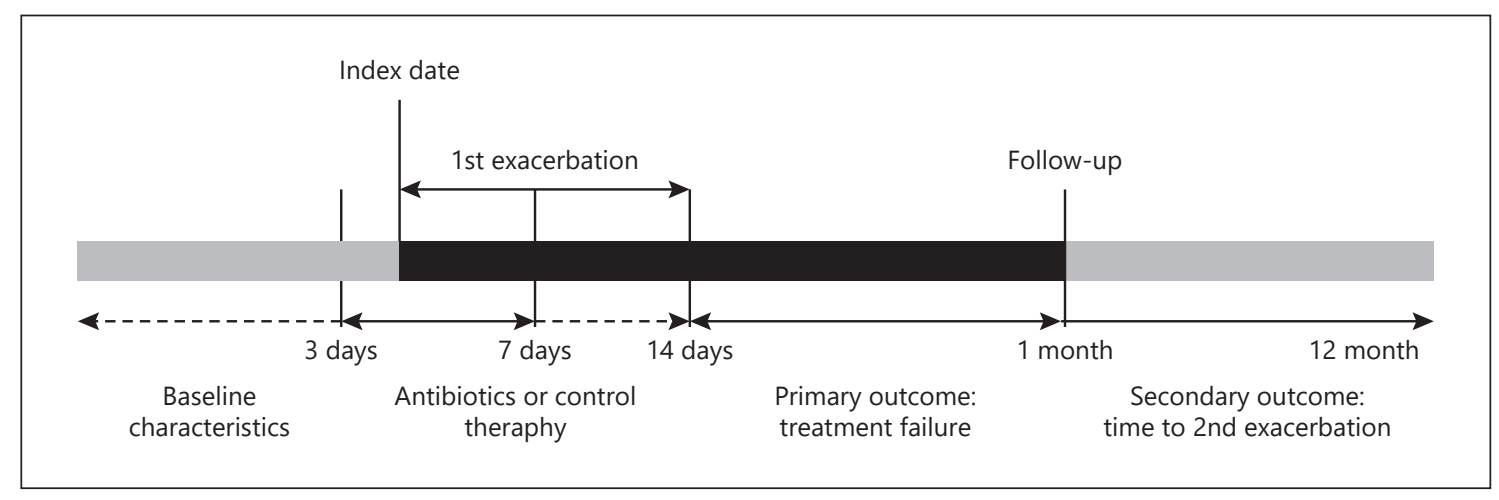

Fig. 1. Observational cohort study design.

\section{Study Population}

From the initial cohort, patients with a clinical diagnosis of COPD who took systemic glucocorticoids for AECOPD were selected for this study according to the following inclusion criteria: (1) patients were entered in both the Lifelines and IADB.nl databases. (2) Patients had spirometrically confirmed COPD with a forced expiratory volume in $1 \mathrm{~s} /$ forced volume capacity $<70 \%$ according to the lung function test or had general practitioner (GP)confirmed COPD according to the record in the Lifelines. The date of the first recorded COPD diagnosis was set as the enrollment date of this study. (3) Patients had the first recorded AECOPD after the enrollment date, which was indicated by the prescription of prednisone or prednisolone treatments (a daily dose of 30-40 mg for 3-7 days with a maximum extension of 14 days) recorded in the IADB.nl database in line with the Dutch College of GPs guideline for COPD management [22]. The date of the first prescription for AECOPD therapy was set as the index date. Of note, according to the key criterion of global initiative for chronic obstructive lung disease (GOLD) to define AECOPD by the need for additional therapy, the AECOPD identified in this study can be classified as moderate AECOPD in which therapy with a systemic course of corticosteroids with or without antibiotics was required. Considering all COPD patients in this study were identified by clinical diagnostic information, we did not set age or other limitations at the stage of study design, but verified the robustness of our results by further substratification of patients.

\section{Exposures and Outcomes}

During the treatment for the first recorded AECOPD with systemic corticosteroid, patients who also received antibiotics within 3 days before and 7 days after the index date were defined as the exposed group. Those who were not prescribed any antibiotic during the same period were defined as the reference group. The short-term outcome was treatment failure defined as any new prescription of prednisolone, prednisone, or antibiotics between 14 and 30 days after the index date. The long-term outcome was the time to next exacerbation defined as a new prescription of prednisone or prednisolone within a 1-year follow-up period. As the first exacerbation may last for a long time, to avoid counting its following treatment as a second exacerbation, we restricted the minimum time from the first to the second exacerbation to 21 days [23]. The study design for the exposure and outcome measurements is described in Figure 1.

Antibiotic Treatment for AECOPD in

Outpatients
Data Collection and Covariates

Age was calculated based on the date of birth and the index date. On the enrollment date, the following information was extracted as covariates from the Lifelines cohort Biobank to describe the characteristics of cohort members with AECOPD: smoking history, GOLD stages of COPD, lung function parameters, and related comorbidities including cardiovascular diseases, diabetes, depression, and other disorders. If information concerning the chronic risk status of AECOPD was not documented on the enrollment date, we used information from the closest follow-up assessment in the Lifelines, if available. Additionally, information on gender, the frequency of AECOPD, and maintenance drugs for $\mathrm{COPD}$ in the previous year before the index date was retrieved from the IADB.nl database.

\section{Subgroup and Sensitivity Analyses}

Given that different antibiotics may have different effects on AECOPD, we conducted a subgroup analysis to explore the effects of 4 specific antibiotic classes (doxycycline, macrolides, co-amoxiclav, and amoxicillin) that are most frequently used due to the recommendation by GOLD or Dutch guidelines. We also further explored the effects of antibiotics for AECOPD therapy among patients with mild COPD and those with more severe COPD. Considering the possible influence of some factors on outcome, we conducted several sensitivity analyses by limiting patients to those with only spirometry-based COPD diagnosis, those with smoking history, those aged 40 or above, and those without asthma-COPD overlap syndrome, respectively, to verify the robust of our results.

\section{Statistical Analysis}

Continuous variables were presented as means with standard deviations or median with interquartile ranges, and Student's $t$ test or Mann-Whitney $U$ test was performed, as appropriate, to examine their difference between the 2 groups. Categorical variables were presented as percentages with $95 \%$ confidence intervals (95\% CI) and compared using a $\chi^{2}$ test or Fisher's exact test, as appropriate. Binary logistic regression analysis was performed to estimate the odds ratio (OR) with a 95\% CI for treatment failure and adjusted for the related covariates that are known risk factors (e.g., age and GOLD stages) and that are unevenly distributed between the exposure groups. This analysis is referred to as covariate adjustment. To better adjust for the differences between groups, propensity score (PS) analysis was also conducted 


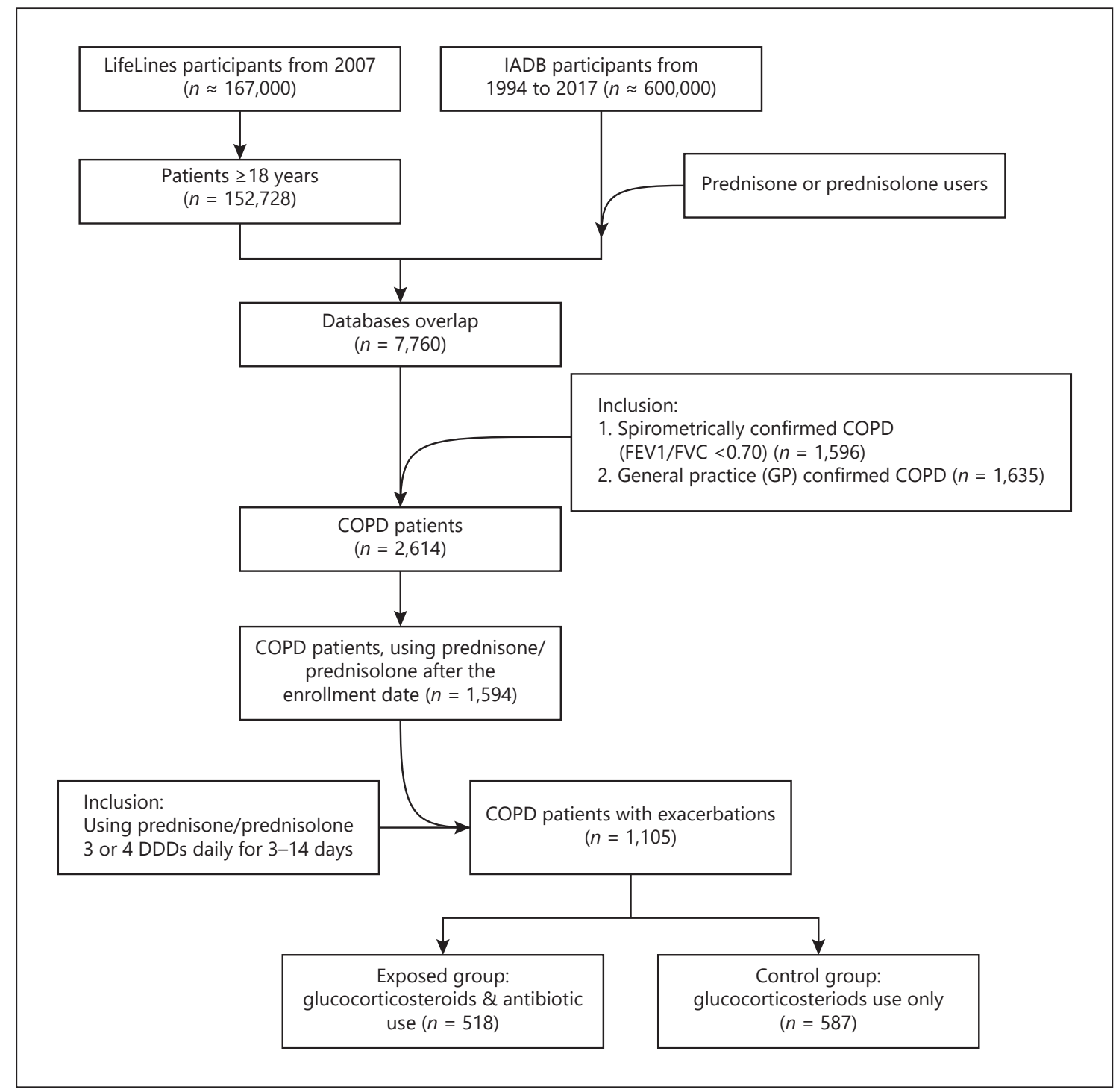

Fig. 2. Flowchart of study subjects selection. COPD, chronic obstructive pulmonary disease; GP, general practitioner; IADB, InterActionDataBase; DDD, defined daily dose.

in 2 steps: the first step was to get the PS by using a backward logistic regression model from all the available data to predict the probability of a patient's exposure to an antibiotic and the second step was to estimate the actual treatment effect by including the PS as a single covariate in the binary logistic regression model. This analysis is referred to as PS adjustment. A Kaplan-Meier survival analysis and log-rank test were conducted to compare the times to the next exacerbations between exposure and reference groups. A Cox proportional hazards regression was performed to estimate the hazard ratio (HR) and 95\% CI for the risk of the next exacerbation. A $p$ value $<0.05$ was considered statistically significant. All analyses were performed using the IBM SPSS statistics version 22 .

\section{Results}

\section{Baseline Characteristics}

The PharmLines Initiative provided information about 7,760 adults who were prescribed a prednisone or prednisolone treatment (Fig. 2). Of these adults, 2,614 (34\%) had a diagnosis of COPD. Of these COPD patients, 1,105 with a first AECOPD recorded after their enrollment dates were finally eligible for our study. In all, 518 patients were enrolled in the exposed group, receiving both systemic glucocorticoids and an antibiotic. 587 patients were enrolled in the reference group, only receiving 
Table 1. Characteristics of outpatients with AECOPD in antibiotic and reference groups $(N=1,105)$

\begin{tabular}{|c|c|c|c|}
\hline Patient characteristics & $\begin{array}{l}\text { Antibiotics } \\
(N=518), n(\%)\end{array}$ & $\begin{array}{l}\text { Reference } \\
(N=587), n(\%)\end{array}$ & $p$ value \\
\hline \multicolumn{4}{|l|}{ Age, years } \\
\hline Median & $55(18)$ & $54(18)$ & 0.24 \\
\hline$\leq 50$ & $185(35.7)$ & $222(37.8)$ & \multirow[t]{3}{*}{0.77} \\
\hline $50-65$ & $189(36.5)$ & $208(35.4)$ & \\
\hline$\geq 65$ & $144(27.8)$ & $157(26.7)$ & \\
\hline \multicolumn{4}{|l|}{ Gender } \\
\hline Male & $211(40.7)$ & $232(39.5)$ & \multirow{2}{*}{0.68} \\
\hline Female & $307(59.3)$ & $355(60.5)$ & \\
\hline \multicolumn{4}{|l|}{$\mathrm{BMI}, \mathrm{kg} / \mathrm{m}^{2}$} \\
\hline Median & $26.9(6.5)$ & $26.4(5.9)$ & 0.24 \\
\hline$\leq 24.9$ & $171(33.0)$ & $203(34.6)$ & \multirow[t]{3}{*}{0.35} \\
\hline $25.0-29.9$ & $195(37.6)$ & $239(40.7)$ & \\
\hline$\geq 30$ & $152(29.3)$ & $145(24.7)$ & \\
\hline \multicolumn{4}{|l|}{ Lung function } \\
\hline $\mathrm{FEV}_{1}, \mathrm{~L}$ & $2.59(1.0)$ & $2.68(1.0)$ & 0.24 \\
\hline FVC, L & $3.86(1.0)$ & $3.96(1.0)$ & 0.13 \\
\hline $\mathrm{FEV}_{1}$ to FVC ratio & $0.68(0.11)$ & $0.67(0.09)$ & 0.77 \\
\hline \multicolumn{4}{|l|}{ GOLD stage } \\
\hline I: mild & $266(59.1)$ & 307 (59.4) & \multirow{3}{*}{0.43} \\
\hline II: moderate & $160(35.6)$ & $193(37.3)$ & \\
\hline III and IV: severe/very severe & $24(5.4)$ & $17(3.3)$ & \\
\hline \multicolumn{4}{|l|}{ Smoking status } \\
\hline Current smoker & $169(35.6)$ & $167(30.8)$ & \multirow{3}{*}{0.25} \\
\hline Former smoker & $190(40.0)$ & $227(41.9)$ & \\
\hline Nonsmoker* & $116(24.4)$ & $148(27.3)$ & \\
\hline \multicolumn{4}{|l|}{ AECOPD in previous year, $n$} \\
\hline 0 & $472(91.1)$ & $557(94.9)$ & \multirow{3}{*}{0.01} \\
\hline 1 & $17(3.3)$ & $17(2.9)$ & \\
\hline 2 or more & $29(5.6)$ & $13(2.2)$ & \\
\hline \multicolumn{4}{|c|}{ Antibiotics prescription in previous year, $n$} \\
\hline 0 & $20(3.9)$ & $322(54.9)$ & \multirow{3}{*}{$<0.01$} \\
\hline 1 & $228(44.0)$ & $139(23.7)$ & \\
\hline 2 or more & $270(52.1)$ & $126(21.5)$ & \\
\hline \multicolumn{4}{|l|}{ Comorbidities } \\
\hline \multicolumn{4}{|l|}{ Cardiovascular diseases } \\
\hline Heart failure & $22(4.2)$ & $12(2.0)$ & 0.03 \\
\hline Heart attack & $23(4.4)$ & $18(3.1)$ & 0.23 \\
\hline Stroke & $<10$ & $11(1.9)$ & 0.87 \\
\hline Arrhythmia & $74(14.4)$ & $78(13.3)$ & 0.63 \\
\hline Hypertension & 165 (31.9) & $180(30.7)$ & 0.67 \\
\hline \multicolumn{4}{|l|}{ Other major disorders } \\
\hline Asthma & $169(32.6)$ & $200(34.1)$ & 0.62 \\
\hline Pulmonary fibrosis & $<10$ & $<10$ & 0.99 \\
\hline Diabetes & $28(5.4)$ & $34(5.8)$ & 0.78 \\
\hline Cancer & $<10$ & $<10$ & 0.79 \\
\hline Osteoporosis & $27(5.2)$ & $21(3.6)$ & 0.18 \\
\hline Renal impairment & $16(3.1)$ & $22(3.7)$ & 0.55 \\
\hline Depression & $83(16.0)$ & $87(14.8)$ & 0.58 \\
\hline Anxiety & $<10$ & $<10$ & 0.26 \\
\hline Anemia & $72(13.9)$ & $78(13.3)$ & 0.77 \\
\hline \multicolumn{4}{|l|}{ Other minor disorders } \\
\hline Ulcerative colitis & $<10$ & $<10$ & 0.03 \\
\hline Stomach ulcer & $24(4.6)$ & $23(3.9)$ & 0.56 \\
\hline Irritable bowel syndrome & $61(11.8)$ & $62(10.6)$ & 0.52 \\
\hline Hepatic impairment & $13(2.5)$ & $10(1.7)$ & 0.35 \\
\hline
\end{tabular}

Antibiotic Treatment for AECOPD in Outpatients
Respiration 2022;101:553-564 DOI: $10.1159 / 000520884$ 
Table 1 (continued)

\begin{tabular}{|c|c|c|c|}
\hline Patient characteristics & $\begin{array}{l}\text { Antibiotics } \\
(N=518), n(\%)\end{array}$ & $\begin{array}{l}\text { Reference } \\
(N=587), n(\%)\end{array}$ & $p$ value \\
\hline \multicolumn{4}{|c|}{ COPD maintenance medications in previous year } \\
\hline SABA & $169(32.6)$ & $183(31.2)$ & 0.61 \\
\hline LABA & $22(4.2)$ & $31(5.3)$ & 0.42 \\
\hline SAMA & $12(2.3)$ & $14(2.4)$ & 0.94 \\
\hline LAMA & $72(13.9)$ & $61(10.4)$ & 0.07 \\
\hline ICS & $67(12.9)$ & $70(11.9)$ & 0.61 \\
\hline LABA/ICS & $190(36.7)$ & $194(33)$ & 0.21 \\
\hline Theophylline & $<10$ & $<10$ & 0.67 \\
\hline
\end{tabular}

Data are presented as mean (SD) or median with IQR or numbers with percentage. Due to privacy protection of patients according to contract, the number below 10 was not permitted to present. AECOPD, acute exacerbation of chronic obstructive pulmonary disease; BMI, body mass index; SABA, short-acting $\beta$ agonist; SAMA, short-acting muscarinic antagonist; LABA, long-acting $\beta$ agonist; LAMA, long-acting muscarinic antagonist; ICS, inhaled corticosteroid; GOLD, global initiative for chronic obstructive lung disease; FEV1, forced expiratory volume in $1 \mathrm{~s}$; FVC, forced vital capacity; SD, standard deviation; IQR, interquartile range. * Identified by those who are neither current smoker nor former smoker based on the record in Lifelines.

Table 2. Odds ratio for treatment failure of index exacerbation among COPD outpatients

\begin{tabular}{lllll}
\hline Treatment groups $(n)$ & $\begin{array}{l}\text { Treatment failure, } \\
n(\%)\end{array}$ & $\begin{array}{l}\text { Crude OR } \\
(95 \% \mathrm{Cl})\end{array}$ & $\begin{array}{l}\text { Adjusted OR } \\
(95 \% \mathrm{CI})^{\mathrm{a}}\end{array}$ & $\begin{array}{l}\text { PS adjusted OR } \\
(95 \% \mathrm{Cl})^{\mathrm{b}}\end{array}$ \\
\hline Reference (587) & $62(10.6)$ & 1 & 1 & 1 \\
All antibiotics (518) & $56(10.8)$ & $1.03(0.70-1.50)$ & $0.67(0.43-1.05)$ & $0.63(0.40-0.99)^{*}$ \\
$\quad$ Doxycycline (214) & $19(8.9)$ & $0.83(0.48-1.42)$ & $0.50(0.26-0.95)^{*}$ & $0.53(0.28-0.99)^{*}$ \\
Macrolides (102) & $11(10.8)$ & $1.02(0.52-2.02)$ & $0.50(0.22-1.15)$ & $0.58(0.26-1.29)$ \\
Amoxicillin (100) & $18(18.0)$ & $1.86(1.05-3.30)$ & $1.56(0.81-3.02)$ & $1.49(0.78-2.84)$ \\
Co-amoxiclav (87) & $<10$ & $0.74(0.33-1.68)$ & $0.48(0.18-1.29)$ & $0.46(0.17-1.24)$ \\
\hline
\end{tabular}

OR, odds ratio; $\mathrm{Cl}$, confidence interval; PS, propensity score. ${ }^{\text {a }}$ Result based on logistic regression with covariate adjustment of age, gender, GOLD stage, smoking status, LAMA prescription, number of antibiotics prescription in previous year, number of AECOPD in previous year, heart failure, and ulcerative colitis. ${ }^{b}$ Result based on logistic regression with propensity score adjustment that PS as a single covariate in the binary logistic regression model. ${ }^{*} p<0.05$.

systemic glucocorticoids. Participant characteristics by treatment groups are described in Table 1. Overall, the measured covariates were very similar between antibiotic and reference groups. The number of previous exacerbations and antibiotic prescriptions as well as the prevalence of heart failures was higher in the exposure group compared with the reference group.

\section{Short-Term Outcome}

Within 14-30 days after treatment of the indexed AECOPD, $56(10.8 \%)$ patients in the antibiotic exposed group versus $62(10.6 \%)$ patients in the reference group experienced treatment failure (crude OR: 1.03 [95\% CI:
$0.70-1.50]$, Table 2). After adjustment for potential confounders (see footnotes in Table 2), the OR decreased in the direction of a beneficial effect of antibiotics, and the adjusted OR (aOR) was 0.67 (95\% CI: 0.43-1.05) and aOR 0.63 (95\% CI: 0.40-0.99) for covariate adjustment and PS adjustment, respectively.

\section{Long-Term Outcome}

Within a year of follow-up after the index date, 153 (29.5\%) patients in the exposure group and 147 (25.0\%) patients in the reference group experienced a next exacerbation (crude HR: 1.14 [95\% CI: 0.87-1.50], see Table 3). After adjustment for confounders (see footnotes in 
Table 3. Hazard ratio for next exacerbation up to 1 year of follow-up after index exacerbation among COPD outpatients

\begin{tabular}{lllll}
\hline $\begin{array}{l}\text { Follow-up time, } \\
\text { months }\end{array}$ & $\begin{array}{l}\text { Antibiotics } \\
\text { group }\end{array}$ & $\begin{array}{l}\text { Reference } \\
\text { group }\end{array}$ & $\begin{array}{l}\text { Crude HR } \\
(95 \% \mathrm{Cl})\end{array}$ & $\begin{array}{l}\text { Adjusted } \mathrm{HR}^{\mathrm{a}} \\
(95 \% \mathrm{Cl})^{\mathrm{a}}\end{array}$ \\
\hline 3 & $57(11.0)$ & $60(10.2)$ & $1.12(0.73,1.74)$ & $1.11(0.71,1.71)$ \\
6 & $109(21.0)$ & $119(20.3)$ & $1.05(0.77,1.43)$ & $1.05(0.77,1.42)$ \\
12 & $153(29.5)$ & $147(25.0)$ & $1.14(0.87,1.50)$ & $1.14(0.87,1.49)$ \\
\hline
\end{tabular}

$\mathrm{HR}$, hazard ratio; $\mathrm{Cl}$, confidence interval. ${ }^{a}$ Adjusted baseline characteristics including age, gender, GOLD stage, smoking status, LAMA prescription, number of antibiotics prescription in previous year, number of AECOPD in previous year, heart failure, and ulcerative colitis by using Cox proportional hazards analysis.

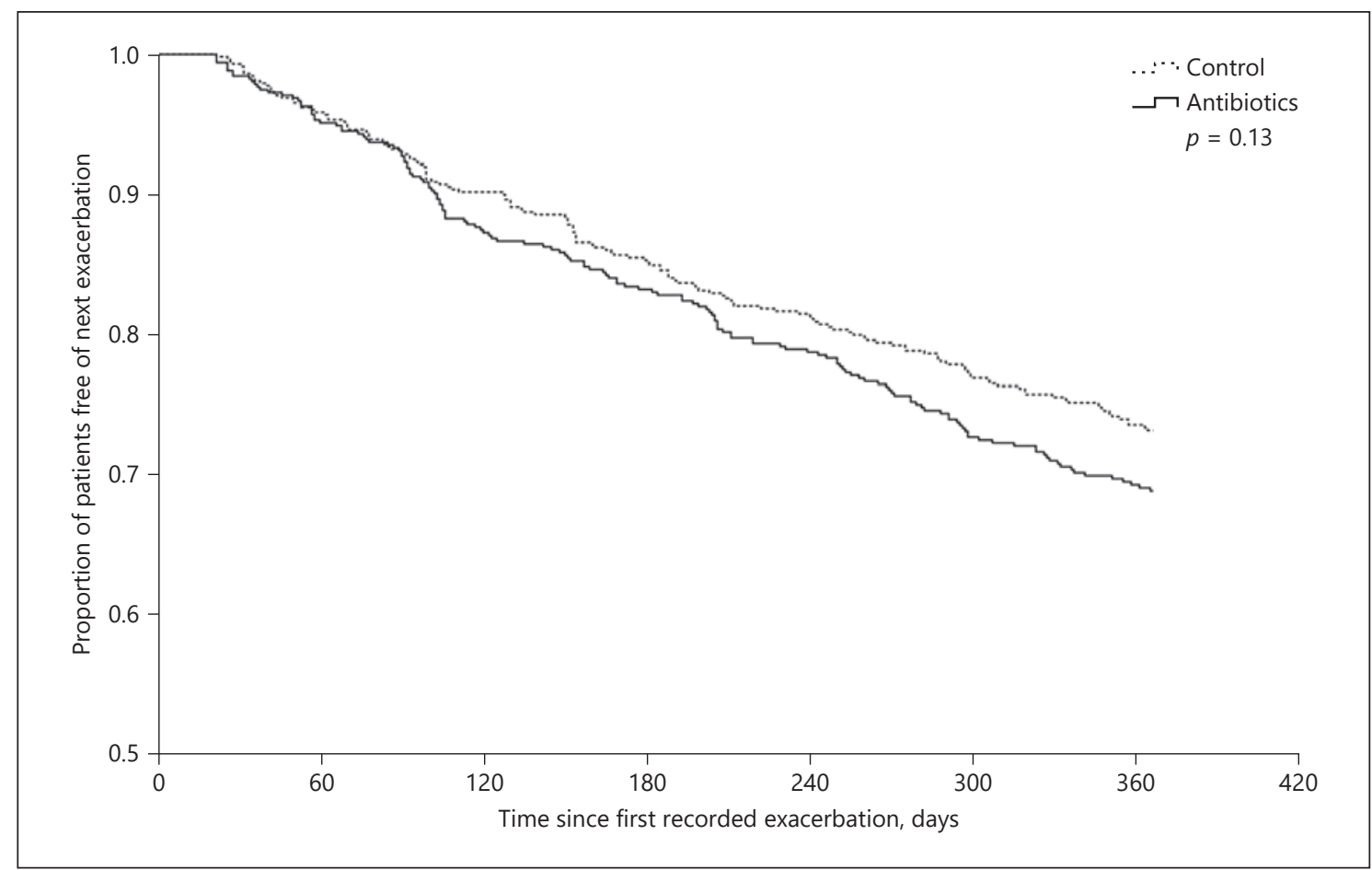

Fig. 3. Kaplan-Meier curves showing the proportion of patients free of next exacerbation in COPD outpatients up to a follow-up of 1 year. COPD, chronic obstructive pulmonary disease.

Table 3), the point estimate of the HR for subsequent exacerbation did not change substantially (covariate adjusted HR 1.14 [95\% CI: 0.87-1.49]). There was also no difference between the 2 comparison groups for the time to the next exacerbation (Fig. 3), which applied to the short follow-up period of 3 and 6 months.

\section{Subgroup and Sensitivity Results}

Among all the antibiotics used for AECOPD treatments in this study for COPD outpatients (Table 2, 518 cases), doxycycline (41.3\%) was the most frequently used antibiotic, followed by macrolides (19.7\%), amoxicillin (19.3\%), and co-amoxiclav (16.8\%), and only 15 cases used other antibiotics (2.9\%). Subgroup analysis indicated that doxycycline significantly reduced the risk of treatment failure by $47-50 \%$ compared to no antibiotic treatment (aOR 0.50 [95\% CI: 0.26-0.95] and 0.53 [95\% CI: $0.28-0.99$ ] for covariate adjustment and PS adjustment, respectively, Table 2). Although not statistically significant, similar beneficial effects were observed for macro- 
Table 4. Sensitivity analyses: odds ratio for treatment failure of index exacerbation among COPD outpatients

\begin{tabular}{|c|c|c|c|c|c|}
\hline \multirow[t]{2}{*}{ Limited COPD patients $(n)$} & \multicolumn{2}{|c|}{ Treatment failure, $n(\%)$} & \multirow{2}{*}{$\begin{array}{l}\text { Crude OR } \\
(95 \% \mathrm{Cl})\end{array}$} & \multirow{2}{*}{$\begin{array}{l}\text { Adjusted OR } \\
(95 \% \mathrm{Cl})\end{array}$} & \multirow{2}{*}{$\begin{array}{l}\text { PS adjusted OR } \\
(95 \% \mathrm{Cl})\end{array}$} \\
\hline & antibiotics & reference & & & \\
\hline With spirometrically confirmed COPD (707) & $30(9.4)$ & $43(11.1)$ & $0.83(0.51,1.36)$ & $0.56(0.32,0.99)^{*}$ & $0.52(0.29,0.90)^{*}$ \\
\hline With smoking history (753) & $47(11.9)$ & $34(9.5)$ & $0.77(0.48,1.23)$ & $0.49(0.29,0.84)^{*}$ & $0.47(0.28,0.80)^{*}$ \\
\hline Aged 40 and over $(1,003)$ & $57(10.8)$ & $53(11.1)$ & $1.03(0.70,1.54)$ & $0.68(0.43,1.08)$ & $0.64(0.40,1.01)^{\#}$ \\
\hline Without COPD-asthma overlap (736) & $36(10.3)$ & $39(10.1)$ & $1.03(0.64,1.66)$ & $0.57(0.31,1.04)$ & $0.57(0.32,1.02)$ \\
\hline
\end{tabular}

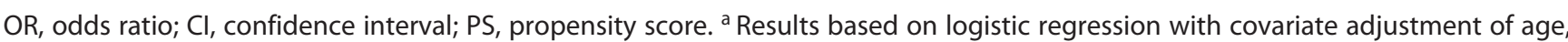
gender, GOLD stage, smoking status, LAMA prescription, number of antibiotics prescription in previous year, number of AECOPD in previous year, heart failure, and ulcerative colitis. ${ }^{b}$ Result based on logistic regression with propensity score adjustment that PS as a single covariate in the binary logistic regression model. ${ }^{*} p<0.05 .{ }^{\#} p=0.07$.

lides (aOR 0.50 [95\% CI: 0.22-1.15] and 0.58 [95\% CI: 0.26-1.29] for covariate adjustment and PS adjustment, respectively) and co-amoxiclav (aOR 0.48 [95\% CI: $0.18-$ 1.29] and 0.46 [95\% CI: 0.17-1.24] for covariate adjustment and PS adjustment, respectively) compared to no antibiotic treatment. No statistically significant difference was observed between the amoxicillin exposed group and the reference group (aOR 1.56 [95\% CI: 0.81-3.02] and 1.49 [95\% CI: 0.78-2.84] for covariate adjustment and PS adjustment, respectively). There was no difference in the observed treatment effects of overall and specific antibiotics in population with mild COPD and population with more severe COPD (online suppl. Table 1; see www.karger.com/doi/10.1159/000520884 for all online suppl. material).

When subjects were further limited to those with spirometrically confirmed COPD, the protective effect of all antibiotics on treatment failure was seen after being adjusted by covariate and PS (aOR 0.56 [95\% CI: 0.32-0.99] and 0.52 [95\% CI: 0.29-0.90], respectively, Table 4). Similar results were found, when limiting the population to those who were former or current smokers (aOR 0.49 $[0.29,0.84]$ and $0.47[0.28,0.80]$ for covariate adjustment and PS adjustment, respectively), when limiting the population to those aged 40 and over (aOR $0.68[0.43,1.08]$ and $0.64[0.40,1.01]$ for covariate adjustment and PS adjustment, respectively), and when limiting the population to those without COPD-asthma overlap (aOR 0.57 [95\% CI: 0.31-1.04] and 0.57 [0.32, 1.02] for covariate adjustment and PS adjustment, respectively). The sensitivity analysis for specific antibiotics in restricted populations among older age and smokers is shown in online supplementary Tables 2 and 3, and results were similar compared with the original study population except for macrolides, which showed statistically significant pro- tective effects for treatment failure in population with smoking history (aOR $0.27[0.09,0.82]$ and 0.30 [0.11, 0.85 ] for covariate adjustment and PS adjustment, respectively).

\section{Discussion}

\section{Primary Findings}

In this study of COPD outpatients with mostly mild to moderate GOLD stages, antibiotic prescription, in addition to systemic glucocorticoids therapy, appeared to reduce the treatment failure of AECOPD after adjusting confounders by PS. Of note, only doxycycline showed statistically significant treatment benefits on AECOPD among the 4 frequently prescribed antibiotics. The supplementation of antibiotic treatment to systemic glucocorticoids did not prolong the time to the next exacerbation for up to 1 follow-up year compared with treatment by only glucocorticoids. Our results, after limiting the COPD patients to those who had spirometrically confirmed COPD, those who were current and previous smokers were still of statistical significance after adjusting by both covariates and PS. However, when limiting the COPD patients to those who aged 40 and over and those without COPD-asthma overlap, although the trends of benefits still existed after adjusting related confounders, the results did not reach statistical significance or just get a boundary significance.

The beneficial effects of antibiotic treatment for AECOPD observed in this study were consistent with the updated pooled results by Vollenweider et al. [11] for outpatients. The finding that additional antibiotic treatment for AECOPD did not produce long-term beneficial effects is also consistent with results of a previous RCT con- 
ducted in COPD outpatients [10]. Conversely, 2 observational studies reported that antibiotic treatment is associated with a reduced risk of a subsequent exacerbation [15, 16]. However, insufficient information in these studies on, for example, lung function, smoking history, and related comorbidities, which are important risk factors associated with AECOPD, could have accounted for these discrepancies [24]. Another difference between our study and the above 2 studies is that we focused on the first recorded AECOPD after diagnosis of COPD in the Lifelines cohort; therefore, only a small proportion of patients had previous AECOPD, and the frequent exacerbator phenotype is likely very uncommon based on our baseline information. Besides, a large part of patients in our study belong to mild COPD with relatively healthy lung functions as is common in Dutch general practice; this may also contribute to the inconsistency of findings between ours and their studies.

GOLD guidelines recommend co-amoxiclav, macrolide, and tetracycline as the first-line antibiotic treatment for AECOPD [4]. The Dutch primary care guidelines recommend amoxicillin or doxycycline as the first-line antibiotics in AECOPD treatment [22]. The combined results of 7 RCTs examined in the updated Cochrane review showed that the antibiotics were generally effective in treating AECOPD in outpatients [11]. However, 3 of these RCTs examined combined antibiotics $[9,25,26]$ and only 4 focused on the specific antibiotics recommended in the abovementioned guidelines: 1 on doxycycline, 2 on co-amoxiclav, and 1 on amoxicillin [10, 2729]. Therefore, no clear conclusion could be drawn about the effects of these specific antibiotics used for AECOPD. Regarding specific antibiotics in our study, doxycycline had significant beneficial treatment effects on AECOPD, which is consistent with 2 guidelines and a recent study [30]. The resistance of common pathogens for AECOPD like $H$. influenzae and S. pneumoniae to doxycycline is reported to be rare in the Netherlands [31], and this may contribute to its successful short-term treatment effects. We observed similar trends toward beneficial effects for macrolides and co-amoxiclav, but nonsignificant, which may be due to the limited sample size to detect effects in subgroup analysis, or due to the bacterial resistance to these antibiotics [32]. However, prescription of amoxicillin that is recommended by the Dutch guideline but not by GOLD guideline did not result into positive effects on AECOPD in both our general and sensitivity analyses. Compared with tetracycline and macrolides, amoxicillin as a narrow-spectrum antibiotic is not effective for all bacterial infections, which makes it not advisable in em-

Antibiotic Treatment for AECOPD in Outpatients pirical antibiotic prescription without a laboratory test. Besides, bacteria often develop resistance to amoxicillin by synthesizing enzymes of $\beta$-lactamase, which could attack the $\beta$-lactam ring to make amoxicillin less effective. In contrast, co-amoxiclav, another penicillin, is a broadspectrum antibiotic, and its ingredient clavulanic acid could inhibit the formation of $\beta$-lactamase and thus help treat infections caused by antibiotic-resistant bacteria [33].

There is a general consensus that exacerbation frequency increases with COPD severity [34]. Because the COPD severity of patients in our study was generally mild (around 60\%) compared with that of patients in previous studies (10-20\%) [10,11], the rate of next exacerbation in our study was relatively low. About $30 \%$ of patients experienced re-exacerbation after index exacerbation within 1-year follow-up. After adjusting for possible confounders, we observed similar rates of next exacerbation between antibiotic users and nonantibiotic users, which is consistent with a previous RCT report [10]. Because the most recommended antibiotics (e.g., macrolides and tetracycline) belong to bacteriostatic that could stop the bacteria from growing or reproduction, but could not totally kill the bacteria, it is understandable that short-term use of an antibiotic may not have longterm effects to prevent another AECOPD, which could be induced by any infection in the future. Although penicillin (e.g., amoxicillin and co-amoxiclav) kills bacteria directly as a bactericidal, they cannot prevent episodes caused by viral infections, which cannot be treated by antibiotics. Of note, if antibiotics were prophylactically used among COPD patients in either continuous or intermittent way, $18 \%$ of subsequent exacerbations could be prevented effectively [35].

Although the presence of purulent sputum is widely deemed to be the sole determinant of antibiotic treatment of AECOPD [4], its accuracy and reproducibility as an indicator of bacterial infection is limited [36], especially for outpatients. Consequently, guidelines on antibiotics prescriptions are not stringently adhered to for treating AECOPD [14]. Inappropriate prescription of antibiotics in general practice is most prominent among adult patients $[13,37]$. Accordingly, we could not exclude the possibility that antibiotic treatment for some patients was incorrectly prescribed due to the empirical antibiotic prescriptions in a real-world setting. Therefore, the effects of antibiotics on AECOPD could be underestimated in the abovementioned real-world setting compared with an ideal situation in which guidelines are fully adhered to in antibiotic prescribing practice. 


\section{Clinical Implications}

Although improper use of antibiotics may occur in a real-world outpatient setting, our findings support the beneficial effect of antibiotics used for AECOPD. Of note, valid and accurate antibiotic prescriptions could not only improve the effects of antibiotic treatments on AECOPD but also reduce antibacterial resistance problems. According to the latest GOLD guideline, the sputum color can be used to avoid unnecessary antibiotic therapy safely with cream, white, or clear sputum indicating very low probability of bacterial infections $[4,12]$. If applicable, although not always feasible, a procalcitonin-guided algorithm or C-reactive protein test can also be considered before making decisions for GP to reduce the unnecessary use of antibiotics [38]. Of note, antibiotics should be prescribed if there is consolidation on a chest radiograph or clinical signs of pneumonia, even without purulent sputum. Moreover, as COPD outpatients are mostly elderly and have lots of comorbidities, the polypharmacy may be very often and could lead to the antibiotic-related drugdrug interactions, which should be noticed while clinicians use antibiotics for AECOPD treatment [39].

Given the significant variability between GP practices of prescribing antibiotics to patients experiencing AECOPD [40], we should keep doxycycline as the first-line antibiotic for AECOPD among Dutch population considering that it is recommended by both GOLD and Dutch guidelines for AECOPD treatment and its beneficial effect was also seen in this real-world study $[4,22]$. If narrow-spectrum antibiotics were considered with valid indicators or results from laboratory tests for specific bacterial infections, co-amoxiclav rather than amoxicillin should be considered first. Although estimates indicate similar beneficial effects for some specific antibiotics, larger studies of high quality with extensive control for potential confounders are needed to explore their role in AECOPD management. Importantly, the final antibiotic choice should also be based on the local bacterial resistance patterns, and sputum cultures of high-risk patients with frequent exacerbations and severe airflow limitations should be performed, given the possible presence of resistant pathogens [4].

\section{Strengths and Limitations}

Our study has several strengths. First, the population in this study was representative of COPD outpatients. Hence, our findings reflect the real-world effects of antibiotic treatment for AECOPD. Second, properly diagnosed COPD patients and their complete background information (e.g., lung function, smoking status, and re- lated comorbidities) that were lacking in previous observational studies were included in this study [30]. Moreover, the outcomes were adjusted for possible confounders using both logistic regression and PS analyses. Sensitivity analyses by further narrowing study population by excluding different sources of uncertainty were also conducted to test the robustness of the results.

There are, however, several potential limitations. First, an acute exacerbation was defined by the prescriptions of prednisone or prednisolone treatment as a proxy according to the Dutch guideline for AECOPD, and this may have led to some misclassifications. Accordingly, this study focused on the effects of antibiotics use in combination with glucocorticosteroids on AECOPD compared with glucocorticosteroids use only; thus, the effects of antibiotics without oral corticosteroids for AECOPD were not covered by this study, which limits our results to be further extrapolated to other types of AECOPD that does not need systemic corticosteroid treatments. Second, different from RCTs, empirical antibiotic prescription in real-world outpatients is common, and incorrect prescription in the absence of confirmed bacterial infections may happen and could lead to an underestimated effect of antibiotics on AECOPD. Third, the relatively low statistical power of subgroup analyses hindered us in making a definitive conclusion regarding the effects of some specific antibiotics on AECOPD. Fourth, clinical events such as hospitalization or death were not available in our databases and therefore were not used as part of the definition of treatment failure, which could bias our results. However, given the relatively mild COPD outpatients with moderate AECOPD severity in both exposure and reference groups, we expect only few patients to have such serious outcomes of hospitalization or death in our study. Finally, there could be differences between countries in the way of managing outpatient AECOPD and use of antibiotics, and thus the results of this study may only be generalizable to those countries who have similar patterns in antibiotic treatment for AECOPD.

\section{Conclusions}

The results of this study support the use of antibiotic therapy, notably doxycycline, for AECOPD in addition to systematic glucocorticoid treatment among outpatients. Treatment effects of other antibiotics for AECOPD need to be explored further in real-world settings. No longterm beneficial effects of antibiotic treatment on AECO$\mathrm{PD}$ were found for subsequent exacerbations. 


\section{Acknowledgments}

The authors wish to acknowledge the services of the Lifelines Cohort Study, the contributing research centers delivering data to Lifelines, and all of the study participants and the participating IADB.nl pharmacies for generous contributions of providing their data for research. They also thank Mr. Jens Bos for his technical support in obtaining the IADB.nl data.

\section{Statement of Ethics}

The Lifelines cohort was approved by the Medical Ethics Committee of the University Medical Center Groningen (code: METc 2007/152), and all participants signed informed consent forms confirming their permission for their (anonymized) data and material to be used for scientific purposes. IADB.nl data are collected in accordance with the national and European guidelines on privacy requirements for handling human data.

\section{Conflict of Interest Statement}

The authors have no conflicts of interest to disclose.

\section{Funding Sources}

The Lifelines Biobank initiative has been made possible by funds received from FES (Fonds Economische Structuurversterking), SNN (Samenwerkingsverband Noord Nederland), and REP
(Ruimtelijk Economisch Programma), and the IADB.nl is funded by the University of Groningen. Yuanyuan Wang acknowledges scholarship funding received from the China Scholarship Council (File No. 201506010259). The funders had no role in study design, data collection and analysis, decision to publish, or preparation of the manuscript.

\section{Author Contributions}

Y.W. and E.H. proposed the initial concept for the study. Y.W. and V.P. collected and performed the initial analysis of data. Y.W. drafted the initial manuscript. H.M.B., J.C.A., B.W., and R.H.H.G. contributed to the interpretation of the data for the work. All the authors critically revised the manuscript for important intellectual content and approved the final version of this manuscript.

\section{Data Availability Statement}

The data that support the findings of this study are available from Lifelines, but restrictions apply to the availability of these data, which were used under license for the current study and not publicly available. Lifelines adheres to standards for data availability. The Lifelines system allows access for reproducibility of the study results, and the data catalog of Lifelines is publicly accessible on www.lifelines.net. All international researchers can apply for data at the Lifelines research office (research@lifelines.nl). Online supplementary Tables 1-3 are available as supplementary data online.

\section{References}

1 Lozano R, Naghavi M, Foreman K, Lim S, Shibuya K, Aboyans V, et al. Global and regional mortality from 235 causes of death for 20 age groups in 1990 and 2010: a systematic analysis for the Global Burden of Disease Study 2010. Lancet. 2012 Dec 15;380(9859): 2095-128.

2 Prins HJ, Duijkers R, van der Valk P, Schoorl M, Daniels JMA, van der Werf TS, et al. CRPguided antibiotic treatment in acute exacerbations of COPD in hospital admissions. Eur Respir J. 2019 May;53(5):1802014.

3 Donaldson GC, Seemungal TA, Bhowmik A, Wedzicha JA. Relationship between exacerbation frequency and lung function decline in chronic obstructive pulmonary disease. Thorax. 2002 Oct;57(10):847-52.

4 Global Initiative for Chronic Obstructive Lung Disease (GOLD). Global strategy for the diagnosis, management and prevention of chronic obstructive pulmonary disease: 2020 report. 2020. Available from: https://goldcopd.org/gold-reports/ Accessed 2019 Dec 17.
5 Walters JA, Tan DJ, White CJ, Gibson PG, Wood-Baker R, Walters EH. Systemic corticosteroids for acute exacerbations of chronic obstructive pulmonary disease. Cochrane Database Syst Rev. 2014;9:CD001288.

6 Sethi S, Murphy TF. Infection in the pathogenesis and course of chronic obstructive pulmonary disease. N Engl J Med. 2008 Nov 27; 359(22):2355-65.

7 Wilkinson TMA, Aris E, Bourne SC, Clarke SC, Peeters M, Pascal TG, et al. Drivers of year-to-year variation in exacerbation frequency of COPD: analysis of the AERIS cohort. ERJ Open Res. 2019 Feb;5(1):002482018.

8 Vollenweider DJ, Jarrett H, Steurer-Stey CA, Garcia-Aymerich J, Puhan MA. Antibiotics for exacerbations of chronic obstructive pulmonary disease. Cochrane Database Syst Rev. 2012 Dec 12;12:CD010257.

9 Hassan WA, Shalan I, Elsobhy M. Impact of antibiotics on acute exacerbations of COPD. Egypt J Chest Dis Tuberc. 2015 Jul;64(3):579_ 85.
10 van Velzen P, Ter Riet G, Bresser P, Baars JJ, van den Berg BTJ, van den Berg JWK, et al. Doxycycline for outpatient-treated acute exacerbations of COPD: a randomised doubleblind placebo-controlled trial. Lancet Respir Med. 2017 Jun;5(6):492-9.

11 Vollenweider DJ, Frei A, Steurer-Stey CA, Garcia-Aymerich J, Puhan MA. Antibiotics for exacerbations of chronic obstructive pulmonary disease. Cochrane Database Syst Rev. 2018 Oct 29;10:CD010257.

12 Kurisu K, Yoshiuchi K, Ogino K, Okada Y, Oda T. Peak C-reactive protein levels do not predict 30-day mortality for bacteremia: a retrospective cohort study. J Infect Chemother. 2020 Jan;26(1):23-7.

13 Roede BM, Bindels PJ, Brouwer HJ, Bresser P, de Borgie CA, Prins JM. Antibiotics and steroids for exacerbations of COPD in primary care: compliance with Dutch guidelines. $\mathrm{Br} J$ Gen Pract. 2006 Sep;56(530):662-5. 
14 Bathoorn E, Groenhof F, Hendrix R, van der Molen T, Sinha B, Kerstjens HA, et al. Reallife data on antibiotic prescription and sputum culture diagnostics in acute exacerbations of COPD in primary care. Int J Chron Obstruct Pulmon Dis. 2017;12:285-90.

15 Roede BM, Bresser P, Bindels PJE, Kok A, Prins M, ter Riet G, et al. Antibiotic treatment is associated with reduced risk of a subsequent exacerbation in obstructive lung disease: an historical population based cohort study. Thorax. 2008 Nov;63(11):968-73.

16 Roede BM, Bresser P, Prins JM, Schellevis F, Verheij TJ, Bindels PJ. Reduced risk of next exacerbation and mortality associated with antibiotic use in COPD. Eur Respir J. 2009 Feb;33(2):282-8.

17 Stefan MS, Rothberg MB, Shieh MS, Pekow PS, Lindenauer PK. Association between antibiotic treatment and outcomes in patients hospitalized with acute exacerbation of COPD treated with systemic steroids. Chest. 2013 Jan;143(1):82-90.

18 Petite SE, Murphy JA. Systemic corticosteroid and antibiotic use in hospitalized patients with chronic obstructive pulmonary disease exacerbation. Ann Pharmacother. 2019 Feb; 53(2): 144-50.

19 Sediq R, van der Schans J, Dotinga A, Alingh RA, Wilffert B, Bos JH, et al. Concordance assessment of self-reported medication use in the Netherlands three-generation lifelines cohort study with the pharmacy database iaDB. nl: the PharmLines initiative. Clin Epidemiol. 2018;10:981-9.

20 Visser ST, Schuiling-Veninga CC, Bos JH, de Jong-van den Berg LT, Postma MJ. The population-based prescription database IADB.nl: its development, usefulness in outcomes research and challenges. Expert Rev Pharmacoecon Outcomes Res. 2013 Jun;13(3):285-92.

21 Scholtens S, Smidt N, Swertz MA, Bakker SJL, Dotinga A, Vonk JM, et al. Cohort profile: lifelines, a three-generation cohort study and biobank. Int J Epidemiol. 2015 Aug;44(4): 1172-80.

22 Snoeck-Stroband JB, Schermer TRJ, Van Schayck CP, Muris JW, Van der Molen T, In 't Veen JCCM, et al. NHG-Werkgroep astma bij volwassenen en COPD. NHG-standard COPD (derde herziening). Huisarts Wet. 2015;58(4):198-211.
23 Seemungal TA, Donaldson GC, Bhowmik A, Jeffries DJ, Wedzicha JA. Time course and recovery of exacerbations in patients with chronic obstructive pulmonary disease. Am J Respir Crit Care Med. 2000 May;161(5): 1608-13.

24 Mullerova H, Shukla A, Hawkins A, Quint J. Risk factors for acute exacerbations of COPD in a primary care population: a retrospective observational cohort study. BMJ Open. 2014 Dec 18;4(12):e006171.

25 Anthonisen NR, Manfreda J, Warren CP, Hershfield ES, Harding GK, Nelson NA. Antibiotic therapy in exacerbations of chronic obstructive pulmonary disease. Ann Intern Med. 1987 Feb;106(2):196-204.

26 Sachs APE, Koeter GH, Groenier KH, Vanderwaaij D, Schiphuis J, Meyboomdejong B. Changes in symptoms, peak expiratory flow, and sputum flora during treatment with antibiotics of exacerbations in patients with chronic obstructive pulmonary-disease in general-practice. Thorax. 1995 Jul;50(7):75863.

27 Jorgensen AF, Coolidge J, Pedersen PA, Petersen KP, Waldorff S, Widding E. Amoxicillin in treatment of acute uncomplicated exacerbations of chronic bronchitis. A doubleblind, placebo-controlled multicentre study in general practice. Scand J Prim Health Care. 1992 Mar; 10(1):7-11.

28 Llor C, Moragas A, Hernández S, Bayona C, Miravitlles M. Efficacy of antibiotic therapy for acute exacerbations of mild to moderate chronic obstructive pulmonary disease. Am J Respir Crit Care Med. 2012 Oct 15;186(8): 716-23.

29 Brusse-Keizer M, VanderValk P, Hendrix R, Kerstjens H, van der Palen J. Necessity of amoxicillin clavulanic acid in addition to prednisolone in mild-to-moderate COPD exacerbations. BMJ Open Respir Res. 2014;1(1): e000052.

30 Wang Y, Bos JH, Boezen HM, Alffenaar JC, van Boven JFM, Schuiling-Veninga CCM, et al. Influence of age on real-life effects of doxycycline for acute exacerbations among COPD outpatients: a population-based cohort study. BMJ Open Respir Res. 2020 Feb;7(1):e000535.
31 Greeff SC, Mouton JW, editors. NethMap 2015: consumption of antimicrobial agents and antimicrobial resistance among medically important bacteria in the Netherlands. Bilthoven: National Institute for Public Health and the Environment; 2015.

32 Martens L, Kuster S, de Vos W, Kersten M, Berkhout H, Hagen F. Macrolide-resistant mycoplasma genitalium in southeastern region of the Netherlands, 2014-2017. Emerg Infect Dis. 2019 Jul;25(7):1297-303.

33 Huttner A, Bielicki J, Clements MN, FrimodtMoller N, Muller AE, Paccaud JP, et al. Oral amoxicillin and amoxicillin-clavulanic acid: properties, indications and usage. Clin Microbiol Infect. 2020 Jul;26(7):871-9.

34 Donaldson GC, Wedzicha JA. COPD exacerbations 1: epidemiology. Thorax. 2006 Feb; 61(2):164-8

35 Wang Y, Zijp TR, Bahar MA, Kocks JWH, Wilffert B, Hak E. Effects of prophylactic antibiotics on patients with stable COPD: a systematic review and meta-analysis of randomized controlled trials. J Antimicrob Chemother. 2018 Dec 1;73(12):3231-43.

36 Siddiqi A, Sethi S. Optimizing antibiotic selection in treating COPD exacerbations. Int J Chron Obstruct Pulmon Dis. 2008;3(1):31-44.

37 Dekker AR, Verheij TJ, van der Velden AW. Inappropriate antibiotic prescription for respiratory tract indications: most prominent in adult patients. Fam Pract. 2015 Aug;32(4): 401-7.

38 Butler CC, Gillespie D, White P, Bates J, Lowe $\mathrm{R}$, Thomas-Jones $\mathrm{E}$, et al. C-reactive protein testing to guide antibiotic prescribing for COPD exacerbations. N Engl J Med. 2019 Jul 11;381(2):111-20.

39 Wang Y, Bahar MA, Jansen AME, Kocks JWH, Alffenaar JC, Hak E, et al. Improving antibacterial prescribing safety in the management of COPD exacerbations: systematic review of observational and clinical studies on potential drug interactions associated with frequently prescribed antibacterials among COPD patients. J Antimicrob Chemother. 2019 Oct 1;74(10):2848-64.

40 Boggon R, Hubbard R, Smeeth L, Gulliford M, Cassell J, Eaton S, et al. Variability of antibiotic prescribing in patients with chronic obstructive pulmonary disease exacerbations: a cohort study. BMC Pulm Med. 2013 May 31; $13: 32$ 